\title{
PERCEPÇÃO DO RUÍDO AERONÁUTICO EM ESCOLAS DA ZONA I DO PEZR DO AEROPORTO INTERNACIONAL SALGADO FILHO
}

\author{
Maria Fernanda de Oliveira Nunes ${ }^{1}$ \\ Miguel Aloysio Sattler ${ }^{2}$
}

Resumo: Neste trabalho é realizada uma avaliação do ruído aeronáutico nas proximidades do Aeroporto Internacional Salgado Filho, em Porto Alegre/RS, com um estudo em duas escolas localizadas dentro da Zona I do Plano Específico de Zoneamento de Ruído - PEZR. O trabalho também apresenta uma breve revisão bibliográfica com a finalidade de fornecer um entendimento geral sobre o ruído aeronáutico. Segundo a Organização Mundial da Saúde, as crianças são consideradas o grupo mais vulnerável aos efeitos do ruído e atualmente, os prejuízos na vida escolar possuem evidências científicas comprovadas. No entanto, as atividades escolares dentro das zonas de ruído mais críticas ao redor dos aeroportos, que não são permitidas segundo legislações nacionais e municipais, ocorrem em ambientes com características construtivas inadequadas aos níveis de exposição. Estão sendo avaliados a percepção e o incômodo do ruído aeronáutico nas escolas localizadas dentro dos limites da Zona I do PEZR do Aeroporto Internacional Salgado Filho, a partir de critérios quantitativos e qualitativos, com medições acústicas, aplicação de questionários, realização de entrevistas, e observações de comportamento e de ocupação dos ambientes nas Escolas. Os resultados iniciais indicam um grande incômodo manifestado por alunos e professores, que convivem em ambientes ruidosos, podendo indicar relações com possíveis problemas vocais e auditivos, em função da necessidade da elevação no volume da voz. Outro aspecto levantado foi o comprometimento do desempenho escolar, decorrente da interrupção na comunicação entre o professor e os alunos durante a passagem dos aviões.

Palavras-chaves: ruído aeronáutico, ambiente escolar, incômodo.

Abstract: This paper aims at evaluating aircraft noise in the vicinity of Salgado Filho International Airport in Porto Alegre, with research done in two schools inside Zone I of Plano Específico de Zoneamento de Ruído - PEZR. It also presents a brief review of studies in order to provide overall understanding about aircraft noise. According to the World Health Organization, children are considered the most vulnerable group regarding the effects of noise. In addition, scientific evidence has proved that school life is harmed. However, school activities inside the most critical noise zones around airports, which are not allowed according to national and municipal legislation, take place in environments with constructive building features unsuitable to the exposure levels. This study aims at evaluating the perception and annoyance of aircraft noise in schools within Zone I of PZER of Salgado Filho International Airport, based on quantitative and qualitative criteria, with acoustics measurement, surveys, interviews, and observation of behavior and use of school environment. The primary results show a lot of annoyance reported by students and teachers who live in noisy environments. Such results may also indicate possible vocal and auditory problems as a consequence of the need to raise one's voice. Another aspect which has been pointed out was problems in school performance because of the frequent interruption in the communication between teacher and students whenever planes flew over the place.

Key words: aircraft noise, school environment, annoyance.

\footnotetext{
${ }^{1}$ Universidade de Caxias do Sul, Curso de Arquitetura e Urbanismo.mfonunes@ucs.br

${ }^{2}$ Universidade Federal do Rio Grande do Sul, PPGEC/NORIE. sattler@vortex.ufrgs.br
} 


\section{INTRODUÇÃO}

Desde sua etapa inicial de construção, os aeroportos são equipamentos urbanos modificadores do meio ambiente e os principais impactos são decorrentes diretamente da operação das aeronaves, como o ruído aeronáutico e a emissão de gases dos motores (ALVES, 2003). Dentre os impactos relacionados à implantação de um aeroporto, como, por exemplo, alterações na qualidade do ar e da água e impactos de construção, o ruído é sem dúvida, o fator determinante de alterações na vida da população que exercem algum tipo de atividade em sua proximidade.

Mesmo sendo considerado, para muitos, como um grande inconveniente, a proximidade com um aeroporto possui vantagens econômicas, no aumento de atividades relacionadas ao transporte aéreo, e sociais, na geração de empregos ligados a essas atividades. No entanto, para que não sejam criados problemas derivados da falta de planejamento, é necessário que na implantação ou ampliação de um aeroporto, sejam realizados estudos de impacto ambiental, considerando a grande influência do ruído aeronáutico na qualidade de vida da população afetada.

O objetivo geral do trabalho é avaliar a percepção e o incômodo do ruído aeronáutico, nas escolas localizadas dentro dos limites da Zona I do PEZR Plano Específico de Zoneamento de Ruído - do Aeroporto Internacional Salgado Filho, a partir de critérios quantitativos e qualitativos.

\section{RUÍDO}

O ruído faz parte do cotidiano de todas as pessoas que residem em centros urbanos, e é de difícil definição, com relação às suas características físicas. Atualmente, ruído pode ser definido como todo o som desagradável ou indesejável ao receptor (GERGES, 2000; ABNT, 1990).

A definição de ruído possui uma componente muito subjetiva, desde que o estímulo sonoro é processado na cóclea e no cérebro e posteriormente submetido a uma interpretação psicológica, a qual varia de indivíduo para indivíduo (SANTOS, 1999). Isso pode ser percebido diante de um número de harmônicos ou freqüências correlatas, nas quais o som total é interpretado, por alguns, como ruído e por outros, como música. No entanto, dependendo do contexto para se entender o tipo de som, é possível considerar um som como ruído ou não. Isto é, o sobrevôo de uma aeronave acima de um certo nível de pressão sonora, poderia ser considerado pela maioria como ruído, porém dependendo do contexto, a música de câmara, no mesmo nível de pressão sonora, no qual o som é considerado como ruidoso, é encarado de modo diferente.

Para se determinar a reação ao ruído, deve-se ir além das medições físicas de exposição ao ruído, por que para uma variedade de sons é necessário que seja considerada uma ampla variedade de reações auditivas entre as pessoas.

O contexto sonoro também é muito importante, no caso da reação ao ruído ocorrer para um som não esperado. Os ruídos aeronáuticos, de tráfego rodoviário e industrial, normalmente são mais aceitáveis por algumas pessoas, devido aos benefícios relacionados às atividades. Porém, essa situação só pode ser aceitável quando o ruído não é percebido ou não é freqüente, em função dos riscos que pode determinar à saúde.

\subsection{O IMPACTO DO RUÍDO AERONÁUTICO NA QUALIDADE DE VIDA}

Muitos estudos apontam a poluição sonora como a forma mais difundida de poluição no mundo atual e a relacionam com danos à saúde das pessoas. A Organização Mundial da Saúde (WHO, 2001) considera que há grupos da população mais vulneráveis ao ruído dos aviões, em comparação com a população geral. O grupo onde há maior evidência de vulnerabilidade ao ruído aeronáutico são as crianças e nelas, a exposição crônica ao ruído dos aviões pode ser 
associada: ao desempenho cognitivo; ao incômodo do ruído; às alterações no bem estar e à baixa motivação; a alterações na pressão sanguínea e à secreção do hormônio catecolamina (adrenalina e noradrenalina); e à secreção do cortisol e distúrbios mentais do sono.

O ruído tem sido considerado, como uma fonte de stress psicológico, tanto que é escolhido como stressor para estudos em laboratório, para se determinar reações ao stress. As reações ao ruído dependem da fonte em si, e das diferenças individuais de reação à fonte de ruído. Os efeitos mais comuns, relacionados ao ruído, dizem respeito ao impacto no sono, riscos para a saúde e o impacto na vida escolar.

\subsubsection{Riscos para a saúde}

Para a Organização Mundial da Saúde, saúde não é considerada como uma mera falta de doença, e sim como o pleno bem estar físico e mental das pessoas. Tal afirmação fortalece a relação entre a exposição permanente ao ruído e os riscos para a saúde de pessoas que convivem em áreas próximas a aeroportos.

Matsui (et al, 2004) realizaram uma pesquisa com 29.000 pessoas residentes nos arredores da base militar de Okinawa, no Japão. Os autores alertam que existem claras relações entre o ruído aeronáutico e a elevação na pressão sanguínea, além da alta tendência de desenvolvimento de hipertensão.

Santos (1999) afirma que a visão pode ser afetada pelo excesso de ruído no momento em que, comprovadamente, há uma dilatação da pupila e a reação de piscar os olhos, que está ligada aos reflexos de convergência e acomodação visual. $\mathrm{O}$ autor ressalta que existe um prejuízo grande nos trabalhos que exigem precisão, em função de que a pessoa teria que ajustar o foco continuamente, aumentando a fadiga e a possibilidade de erros.

Outros efeitos na área da saúde também são notados nos locais ao redor dos aeroportos. Knipschild e Oudshoorn (apud MUZET, 2001) relataram o aumento na prescrição de remédios em torno de grandes aeroportos, e
Tarnopolsky et al (apud MUZET, 2001) registraram aumentos na admissão de pacientes em hospitais psiquiátricos. Santos (1999) descreve que as alterações neuropsíquicas, como ansiedade, insegurança e desconfiança, também podem ser associadas ao excesso de exposição ao ruído.

\subsubsection{Ruído e performance escolar}

O aprendizado é uma das principais atividades na vida das pessoas e, mesmo não estando em ambientes destinados ao ensino, o processamento de novas informações a partir da interação com o meio, faz com que o processo seja contínuo. Fischer (2000), estudou a relação entre o ambiente escolar e o comportamento dos usuários, avaliando a percepção ambiental em três escolas de Porto Alegre. Em sua pesquisa, a autora levantou aspectos relativos à aparência, flexibilidade, segurança, privacidade, acessibilidade e conforto ambiental nas escolas. Com relação ao conforto acústico, Fischer identificou que, os problemas relativos à exposição ao ruído são recorrentes, denotando a total falta de conhecimento do problema por parte dos projetistas.

No Brasil, o assunto ainda é recente, com poucos estudos relativos ao ruído aeronáutico, sendo que alguns estudos (PAIXÃO, 1997; SANTOS, 1993; LOSSO, 2003) relacionam o ruído ambiente com a performance escolar das crianças. Bertoli et al (1999) avaliaram a implantação de três creches em um conjunto habitacional em São Paulo, situadas no cone de aproximação do Aeroporto Internacional de Guarulhos, e mesmo tendo um grande fluxo de aeronaves, uma a cada 2 minutos, o ruído aeronáutico não é percebido em função do ambiente ruidoso da escola. Em todos os estudos foi ressaltada a deficiência de projeto das edificações.

Em outros países, a relação entre ruído aeronáutico e performance escolar tem sido muito estudada e vários pesquisadores apontam que o vocabulário utilizado por crianças que convivem em ambientes silenciosos é melhor. As crianças, em condições silenciosas, gostam mais de falar, elas são mais bem 
entendidas pelos outros, e entendem o que os outros dizem.

Segundo Gifford (1998), a relação entre ruído e aprendizado é complexa e depende de fatores como: as propriedades do ruído em relação à continuidade e grau de intensidade; a característica do aluno: sexo, motivação, personalidade, inteligência, autocontrole; a natureza da tarefa: leitura, recreação, avaliação, e a situação em relação à hora do dia.

Gifford (1998) alerta que as crianças expostas ao ruído apresentam um rendimento escolar abaixo do normal e que a agressividade nos adolescentes, em ambientes barulhentos, pode ficar maior. De um modo geral, segundo o autor, o desempenho escolar do aluno fica comprometido pela interferência no processo de comunicação entre 0 professor e o aluno, causando distorções nas informações. Gifford estabelece algumas relações entre ruído e aprendizado, com forte dependência de alguns fatores: o ruído em sala de aula prejudica mais as meninas que os meninos; quando a tarefa possui um grau de dificuldade maior, todos são afetados; o autocontrole do aluno é afetado em função do aumento da pressão sanguínea.

Os estudos conduzidos sobre a influência do ruído aeronáutico nas habilidades necessárias na fase de préalfabetização são poucos. Maxwell e Evans (2000) realizaram uma pesquisa que mostrou uma forte ligação entre a exposição crônica ao ruído e habilidades de leitura necessárias na fase de préalfabetização, focalizando as habilidades de atenção. Segundo os autores, as crianças em idade pré-escolar são afetadas negativamente por tal exposição. O estudo incluiu a aplicação de testes cognitivos em crianças de 4 anos, antes e depois do tratamento acústico da sala de aula.

Hambrick-Dixon (apud MAXWELL e EVANS, 2000), investigou habilidades de atenção em crianças, também de 4 anos, na fase de pré-alfabetização. O autor descobriu que as crianças que freqüentam escolas em áreas barulhentas possuem uma performance melhor em condições ruidosas, enquanto que as crianças em escolas silenciosas, executaram melhor o teste, em circunstâncias com ausência de barulho.

Maxwell e Evans (2000) colocam que as crianças mais novas possuem mais facilidade de adaptação às características ambientais, por isso elas são menos afetadas em locais ruidosos. Heft (apud MAXWELL e EVANS, 2000) relatou descobertas similares para as crianças do jardim de infância, expostas ao som da fala durante uma tarefa de discriminação visual. No estudo de Heft, de 1979, as crianças de lares ruidosos se distraíram menos durante a tarefa, do que crianças de lares silenciosos. O trabalho de Cohen et al (1980), entretanto, indica que a vantagem apontada por Helft é perdida em curto prazo, à medida que a criança cresce.

Uma explicação do porquê das crianças da pré-escola, acostumadas a um ambiente ruidoso, não se distraírem com o ruído durante uma tarefa, segundo Maxwell e Evans (2000), é que as crianças são capazes de selecionar os estímulos externos, enquanto aquelas dos ambientes quietos não precisam desenvolver essa habilidade.

Analisando os estudos feitos, é possível afirmar que o ruído crônico pode afetar negativamente as crianças na fase de pré-alfabetização, mas que as conseqüências podem não ser evidentes até alguns anos mais tarde.

Jiggins e Berry (2001) realizaram uma pesquisa em escolas do lado ocidental de Londres, com exposição crônica ao ruído aeronáutico nos arredores do Aeroporto de Heathrow. O objetivo principal consistiu em verificar se os níveis previstos para as áreas, em 1997, continuavam caracterizando a área como de intensa exposição ao ruído, além de avaliar o efeito da exposição crônica ao ruído aeronáutico, na performance cognitiva (leitura, memória e atenção) e em indicativos de stress (nível de catecolamina, incômodo e relato próprio de stress) em crianças.

Os resultados confirmaram que as escolas estão localizadas em áreas de exposição intensa ao ruído aeronáutico, 
conforme as curvas determinadas em 1997. Os testes cognitivos apontaram deficiências de leitura, com manifestação representativa de elevado nível de incômodo, confirmando estudos anteriores. Os resultados dos testes de atenção e memória não tiveram relação direta com a exposição crônica ao ruído, assim como não foram verificadas relações com o stress, segundo os exames clínicos das taxas de cortisol. A conclusão do trabalho apontou que a exposição crônica ao ruído aeronáutico, não está relacionada aos danos gerais na performance cognitiva, e sim em determinadas habilidades cognitivas.

Haines et al. (apud BOMAN e ENMARKER, 2004) também conduziram um estudo perto do aeroporto de Heathrow, com crianças entre 8 e 11 anos. Foi verificado que a exposição crônica ao ruído dos aviões esteve associada com os níveis mais elevados do incômodo, porém não foram medidos os principais efeitos encontrados na menor compreensão de leitura. Depois de um ano, a exposição ao ruído aeronáutico foi associada com um nível ainda mais elevado do incômodo. Além disso, um maior número de crianças relatou a interferência do ruído do avião nas suas atividades da sala de aula, como, por exemplo, trabalhar e pensar.

\subsection{MEDIÇÃO DO EVENTO DE RUÍDO AERONÁUTICO}

A medição do ruído aeronáutico é uma ferramenta indispensável no estudo de impacto ambiental de um aeroporto. Porém, inúmeras variáveis podem contribuir para o fracasso de uma medição. O problema mais comum é o de discriminar a diferença entre o ruído originado da passagem de uma aeronave e outro ruído, originado de uma fonte eventual. Por exemplo, o programa de monitoramento de ruído de alguns aeroportos envolve a medição em estações móveis, composta por um veículo dotado dos equipamentos necessários à medição, que é deslocado periodicamente na comunidade vizinha, e que freqüentemente pode captar sons como latidos de cachorros ou crianças brincando.
Segundo Wallis (2002), apenas no início dos anos 90 surgiu o primeiro equipamento para monitoramento do ruído de aeroportos, com uma sofisticação que permitiu uma melhor definição dos dados. A empresa do Reino Unido Cirrus Research introduziu o sound gate permitindo uma precisão de $98 \%$.

O perfil típico em um gráfico de um sobrevôo se caracteriza por uma linha de saída do nível sonoro, seguido de uma linha de descida. Porém não se observa um platô na duração. Ademais, o valor máximo do nível da curva de saída depende da constante de tempo adotada. Segundo Farina (1995), aumentando o tempo de integração do equipamento, reduz-se o valor máximo resultante da medição. Logo, a constante de tempo FAST oferece um gráfico mais detalhado, em comparação ao da constante $S L O W$, assim como o tempo de integração de 1 segundo, que apresenta um perfil mais detalhado, se comparado ao de 2 segundos.

\subsubsection{Recomendações da ISO 3891}

A norma ISO 3891 (1978) fornece os procedimentos para identificar o ruído proveniente das operações das aeronaves, especificando a finalidade para quais esses métodos podem ser usados, incluindo certificação de aeronaves, monitoramento de níveis de ruído ou de exposição ao ruído, e planejamento de uso do solo. Os procedimentos dividemse em dois níveis de sofisticação de medições:

a) Aquelas que requerem análise espectral em função do tempo, usada para certificação de aeronaves, na qual é requerida uma alta confiabilidade de resultados;

b) Aquelas que requerem apenas a freqüência ponderada, onde a sofisticação das medições é reduzida por simplicidade ou baixo custo.

Deve-se ressaltar que, o segundo procedimento se diferencia do primeiro por não exigir a análise espectral em $1 / 3$ de oitava, e permitir a medição apenas do nível máximo. 
Para medições de exposição ao ruído, devido a uma sucessão de operações, a norma recomenda o uso do segundo procedimento, para se obter as características de ruído de cada aeronave, com os resultados expressos em $\mathrm{L}_{\text {EPN }}$ ou $\mathrm{L}_{\mathrm{AX}}$ para cada ponto de medição. No entanto, também é indicado o uso do primeiro procedimento para se obter dados mais refinados (ISO, 1978, p. 10).

Ambos os procedimentos indicam que deve ser usado um microfone onidirecional, com características dinâmicas $S L O W$, na ponderação D ou A. Em casos especiais, por exemplo, em vôo baixo de uma aeronave em alta velocidade, a característica dinâmica FAST pode ser necessária para se obter uma medição mais representativa. A diferença básica entre o uso das características FAST ou SLOW do equipamento foi apresentada anteriormente (FARINA, 1995) e pode ser explicada sucintamente da seguinte maneira: a constante FAST proporciona dados mais detalhados, porém apresenta o $\mathrm{L}_{\max }$ maior em relação a constante SLOW.

Ainda com relação ao microfone recomendado pela ISO (1978), Gerges (2000) explica que existem três tipos de microfones de pressão, que são projetados para responder na direção tangencial da membrana: de resposta de pressão, de resposta campo livre e de resposta campo aleatório. Esse último, chamado também de onidirecional, é o recomendado pela ISO 3891.

A ISO também determina que as condições físicas do ambiente escolhido para as medições devem ser as seguintes:

a) não pode haver obstrução;

b) o ruído de fundo não pode ser percebido e, segundo a referida norma, as medições de ruído serão consideradas confiáveis, apenas quando a medida máxima de nível de ruído da aeronave exceder o nível de ruído de fundo, em no mínimo, $20 \mathrm{~dB}$;

c) a superfície do solo não deve possuir absorção sonora excessiva, como, por exemplo, aquelas que possuem algum tipo de vegetação; d) o material de referência em relação ao coeficiente de absorção é o concreto;

e) a superfície do solo deve ser horizontal, dentro de uma tolerância de 3 graus de inclinação; f) as pessoas também são consideradas como obstruções;

g) a velocidade do ar não deve ser maior que $5 \mathrm{~m} / \mathrm{s}$, considerando uma altura de $10 \mathrm{~m}$ acima do solo.

As condições atmosféricas possuem grande influência na propagação do som e para que haja confiabilidade nos dados coletados, as medições não devem ser realizadas na ocorrência de precipitações, e, para umidade relativa menor que $20 \%$, a temperatura atmosférica não deve ser menor que $5^{\circ} \mathrm{C}$.

\subsection{2 Índices de exposição da população ao ruído aeronáutico}

Um índice é uma expressão matemática utilizada para representar uma situação complexa, variável no tempo e no espaço. Pode-se admitir que um índice acústico é a expressão de uma determinada situação. Sendo assim, uma ferramenta que permite medir e comparar a situação do ruído em diferentes locais, em diferentes momentos do dia ou do ano. O índice é utilizado, no caso do ruído aeronáutico, para definir zonas ao redor dos aeroportos e definir urbanisticamente os diferentes setores, conciliando o uso do solo e a exploração dos aeródromos. Um índice pode, então, permitir o controle da qualidade sonora ao redor dos aeroportos, levando-se em conta o evento diário da passagem de um avião ruidoso durante o dia, e ainda, em longo prazo, a evolução do ruído ano a ano. (VALLET, 1996).

Segundo Sancho e Senchermes (1982), no caso da determinação do impacto do ruído aeronáutico em áreas vizinhas aos aeroportos, é importante considerar o número de operações em um determinado período de tempo. O conceito de ruído e número constitui a base de, praticamente, todos os índices de exposição ao ruído aeronáutico, representando um número de eventos, em um determinado período de tempo. Os autores esclarecem, ainda, que, no caso 
do ruído aeronáutico, se fala em índice de exposição e não em nível de ruído existente, que é apenas um dos fatores que compõem o índice de exposição.

Segundo Vallet (1996), os índices devem possuir várias características, dentre as quais se destacam as seguintes:

a) boa representação do incômodo, estabelecendo relações com as diferentes variáveis envolvidas. Por exemplo: diferença entre os períodos da manhã, tarde e noite ${ }^{3}$;

b) precisão na descrição dos níveis de ruído e do período de referência;

c) facilidade de emprego, tanto na medição como nos cálculos de previsão;

d) clareza de formulação, incluindo o tipo de medidas práticas que possam ser tomadas;

e) coerência regulamentar, sendo preferencialmente definido por uma norma nacional ou internacional;

f) facilidade de entendimento para comunicação entre os administradores, comunidades vizinhas e população em geral. Esse ponto, em particular, segundo Vallet (1996), possui atualmente uma importância cada vez maior.

O incômodo devido ao ruído aeronáutico tem sido avaliado na França por meio de vários levantamentos. A pedido dos Ministérios do Meio Ambiente e dos Transportes, o INRETS ${ }^{4}$ realizou uma pesquisa para coleta de dados relacionados à exposição ao ruído e incômodo, relatada em artigo de Vincent et all (2000). O objetivo foi verificar se o índice IP, utilizado na França para estudos de planejamento urbano, ainda era adequado. $\mathrm{O}$ estudo também teve como finalidade, determinar qual o índice acústico que mais considera o incômodo, além de testar os índices $\mathrm{L}_{\mathrm{eq}}$, $\mathrm{L}_{\mathrm{DN}}, \mathrm{L}_{\mathrm{DEN}}$, onde foi verificada uma

\footnotetext{
${ }^{3}$ Essa diferença é estabelecida através de uma ponderação para cada período do dia.

${ }^{4}$ Institut National de Recherche sur lês Transports et leur Sécurité: Instituto Nacional de Pesquisa em Transportes e Segurança.
}

ENGEVISTA, v. 6, n. 3, p. 5-24, dezembro 2004 correlação estatística muito fraca entre os índices e o incômodo da população.

Um outro fator notado na pesquisa, diz respeito à localização da edificação de cada pessoa, pois aquelas que moram embaixo da trajetória das aeronaves, possuem um nível de incômodo maior do que aquelas que moram nas laterais das pistas, sem um vínculo claro com o medo de acidentes. Estudos anteriores na França e no Reino Unido, mostraram que o incômodo aumenta com o ruído. Mesmo que a relação estatística seja fraca, duas principais informações principais podem ser destacadas:

a) $\mathrm{O}$ incômodo depende de muitas variáveis da exposição ao ruído, no espaço e tempo, e para pessoas que residem em um local em particular; b) $\mathrm{O}$ incômodo é expresso segundo fatores pessoais, psicológicos, sociológicos e econômicos, que são, por definição, não acústicos.

Outras reações também são relevantes: as exigências humanas em questões relacionadas ao meio ambiente têm aumentado durante as últimas décadas. Um exemplo desse fato é encontrado no Aeroporto de Dusseldorf, onde o tráfego aéreo tem aumentado e os níveis de ruído têm diminuído, desde 1987 (KATSKA et all apud VINCENT, 2000), porém a porcentagem de pessoas incomodadas está progressivamente aumentando. Conseqüentemente, a relação entre níveis de ruído e incômodo expresso está decaindo. Vários fatores, considerados como não acústicos, parecem aumentar o incômodo - como, por exemplo, o número de operações, o medo do aumento do tráfego numa segunda pista, o aumento na sensibilidade - sem o aumento dos níveis de ruído. Foi concluído que os índices $\mathrm{L}_{\mathrm{eq}} \mathrm{e} \mathrm{L}_{\mathrm{DN}}$, correspondem melhor à expectativa das pessoas que moram próximo aos aeroportos, em termos de entendimento da exposição ao ruído e melhoria da aceitação. Na avaliação dos autores, os referidos índices se mostram adequados no sentido de serem mais simples de medir ou calcular, e de melhor entendimento para os habitantes. 


\subsubsection{Curvas Isofônicas}

As curvas isofônicas representam a união de pontos com a mesma avaliação numérica, ou nível de ruído, no entorno de um aeroporto. Leva-se em consideração a possibilidade de se obter os níveis de incômodo, para um determinado período, um dia, por exemplo, obtendo-se um conjunto de contornos, ou curvas, de igual nível de incômodo.

A geração de curvas através de medições é uma atividade complexa, envolvendo um investimento muito alto na compra de equipamentos de precisão e um controle rigoroso sobre as variáveis que podem afetar a confiabilidade dos dados. Muitos aeroportos, atualmente, utilizam um sistema de monitoramento do ruído, com a finalidade de verificar valores estipulados em simulações. Através dessas curvas, pode-se avaliar a extensão do impacto sonoro produzido pelo aeroporto, além de analisar quantitativamente os efeitos de soluções imaginadas. Dessa forma, pode-se elaborar uma política de ocupação do solo, que harmonize a convivência entre o aeroporto e a comunidade servida. (IAC, 1981, p. 38).

A idéia de geração desse tipo de curva surgiu nos Estados Unidos, após a Segunda Guerra Mundial, em virtude da multiplicação de bases aéreas pelo interior do país e o surgimento das primeiras aeronaves militares a jato. Como essas bases foram instaladas, predominantemente, em áreas rurais ou semi-rurais, o impacto sonoro se tornou muito mais significativo devido à diferença entre o ruído das aeronaves e o ruído de fundo. A reação das comunidades ao problema gerado pelas bases aéreas, obrigou a Força Aérea Americana a estudar o problema com a finalidade de encontrar soluções. Os primeiros resultados desses estudos surgiram em 1952, e várias adaptações foram apresentadas como, por exemplo, a inclusão de uma diferenciação para os períodos de inverno e verão e a duração de cada evento (IAC, 1981). O nível de pressão sonora assim obtido foi denominado equivalent continuous sound pressure level, nível equivalente de pressão sonora contínua, ou simplesmente $L_{\text {eq }}$, onde é levada em consideração a duração do evento.

A comparação resultante dos valores de $\mathrm{L}_{\mathrm{eq}}$ era relacionada a possíveis reações comunitárias classificadas segundo três categorias, conforme a tabela a seguir:

Tabela 1: Níveis de ruído e reações comunitárias segundo Stevens e Pietrosanta.

\begin{tabular}{|l|l|}
\hline Descrição da Rede Comunitária & $\mathbf{L}_{\mathbf{e q}}$ \\
\hline $\begin{array}{l}\text { Nenhum descontentamento foi } \\
\text { relatado. O ruído pode, entretanto, } \\
\text { interferir ocasionalmente com } \\
\text { atividades dos residentes. }\end{array}$ & $\begin{array}{l}\text { Menor } \\
\text { que } 45 \mathrm{~dB}\end{array}$ \\
\hline $\begin{array}{l}\text { Alguns residentes na comunidade } \\
\text { podem reclamar, talvez } \\
\text { vigorosamente. Ações em grupo } \\
\text { contra as autoridades não devem } \\
\text { existir, mas a possibilidade destas } \\
\text { ações existe. }\end{array}$ & $\begin{array}{l}\text { De } 45 \mathrm{~dB} \\
\text { a dB }\end{array}$ \\
\hline $\begin{array}{l}\text { Reações comunitárias contra as } \\
\text { autoridades existirão. As atitudes } \\
\text { podem variar de fortes ameaças a } \\
\text { ações vigorosas. }\end{array}$ & $\begin{array}{l}\text { Maior que } \\
55 \mathrm{~dB}\end{array}$ \\
\hline
\end{tabular}

(IAC, 1981, p. 36)

Observando a tabela anterior, podese afirmar, que na época, década de 50 , a preocupação das autoridades militares não estava relacionada com o transtorno do ruído aeronáutico na comunidade e sim, com o tipo de incômodo que a comunidade poderia causar em função dos níveis de ruído.

Em 1978, a FAA desenvolveu um software para previsão do impacto do ruído aeronáutico, tendo como base um modelo para estimar a evolução do impacto do ruído aeronáutico em áreas vizinhas aos aeroportos, produzindo curvas isofônicas, denominado INM (FAA, 2004). Para gerar as curvas de ruído, o modelo utiliza informações referentes ao aeroporto, movimento das aeronaves, operações de vôo e a definição do índice de ruído. Na versão de 1982, utilizada em um estudo feito na Espanha, nos seis maiores aeroportos espanhóis (GARCIA, FAUS e GARCIA, 1993), havia quatro índices pré-definidos: NEF, $\mathrm{L}_{\text {Aeq, }} \mathrm{L}_{\mathrm{DN}}, \mathrm{TA}$, e apenas 66 tipos de aeronaves comerciais e militares. A versão atual possui mais de 16 índices pré-definidos, como também pode 
trabalhar com índices específicos de determinados países, como o ANEF na Austrália. A base de dados de aeronaves também foi ampliada, contando, atualmente, com 101 tipos de aeronaves civis (FAA, 2004).

\section{3 ÍNDICE PONDERADO DE RUÍDO IPR}

No Brasil, o método utilizado para medir o incômodo causado pelo ruído aeronáutico é o IPR, Índice Ponderado de Ruído, que, segundo o IAC (1981), foi criado com a finalidade de avaliar o incômodo, a partir da geração de curvas isofônicas. O IPR é um método muito parecido com o WECPNL com algumas características do NEF. Foram mantidos os pesos diferenciados para vôos diurnos e noturnos e o período de referência foi restringido para um dia, com a exclusão do ajuste sazonal.

As autoridades aeronáuticas no Brasil consideram que o fator de maior peso não é o incômodo sentido pelas pessoas, e sim a forma como elas reagem ao incômodo. Muitos estudos apontam uma forte relação entre a reação ao incômodo, o nível sócio-econômico e as atividades exercidas nas áreas afetadas. De um modo geral, quanto maior o nível sócio-econômico da população, maior será a restrição à poluição sonora. Desta forma, foi elaborado um quadro, no qual estão relacionados valores de IPR e a reação esperada da comunidade.

Tabela 2: Valores de IPR e reações comunitárias.

\begin{tabular}{|l|l|}
\hline Valor do IPR & $\begin{array}{l}\text { Reação da comunidade } \\
\text { exposta a este nível de ruído }\end{array}$ \\
\hline $\begin{array}{l}\text { Menor que 53 } \\
\text { IPR }\end{array}$ & $\begin{array}{l}\text { Nenhuma reclamação é } \\
\text { esperada. Ambiente pouco } \\
\text { ruidoso. }\end{array}$ \\
\hline $\begin{array}{l}\text { Entre 53 e } 60 \\
\text { IPR }\end{array}$ & $\begin{array}{l}\text { Ambiente medianamente } \\
\text { ruidoso. É esperado grande } \\
\text { volume de reclamações por } \\
\text { parte dos residentes. }\end{array}$ \\
\hline Maior que 60 & $\begin{array}{l}\text { Ambiente extremamente } \\
\text { ruidoso. São esperadas } \\
\text { reclamações generalizadas por } \\
\text { parte dos residentes. É possível } \\
\text { ação comunitária em prol da } \\
\text { redução do ruído. }\end{array}$ \\
\hline
\end{tabular}

(IAC, 1981, p. 96)

A relação estabelecida é muito semelhante ao que foi visto anteriormente na Tabela 1 , onde as autoridades militares norte-americanas na década de 50 relacionavam índices de ruído com reações da comunidade. Pode-se interpretar essa relação como uma forma de precaução das autoridades aeronáuticas, no sentido de se defender do incômodo que a comunidade possa causar com reclamações e ações judiciais. A relação estabelecida não mostra uma intenção clara de preocupação com aspectos relacionados aos efeitos do ruído causados na comunidade.

\subsection{O RUÍDO AERONÁUTICO NOS AEROPORTOS}

Os impactos gerados pela operação dos aeroportos podem ser identificados segundo quatro tipos de fatores (Horonjeff apud ALVES, 2003): fatores de poluição, fatores sociais, fatores ecológicos e fatores econômicos e de engenharia. O ruído é considerado um aspecto dentro dos fatores de poluição, juntamente com a qualidade do ar, qualidade da água e impactos de construção.

A preocupação com o ruído tem levado alguns países a considerar a possibilidade de proibir a operação de certas aeronaves ruidosas em seus aeroportos. No entanto, as restrições deste tipo podem ter conseqüências econômicas significativas para as empresas aéreas, tanto para as estabelecidas nos países que adotam essas medidas, como as estabelecidas em outros países, particularmente nos países desenvolvidos, que prestam serviços, direta ou indiretamente, na fabricação de aeronaves. As empresas aéreas terão que trocar suas aeronaves por outras mais novas, ou recondicionadas com motores mais silenciosos, e com equipamento de atenuação de ruído, ou transferir as aeronaves mais ruidosas para outras rotas. (ICAO, 2000)

Na Europa, a aviação é o meio de transporte de maior crescimento, com um aumento de $6 \%$ ao ano, e com uma projeção de duplicação do tráfico aéreo em 2015. Esse dado traz uma preocupação em relação ao aumento da área de alguns dos maiores aeroportos europeus, e seu conseqüente impacto na 
malha urbana das cidades. Güller e Güller (2002) afirmam que o nível de aceitação das comunidades vizinhas, em relação à ampliação dos aeroportos, é inversamente proporcional à exposição ao ruído. Em 2000, foi realizada uma votação na comunidade vizinha ao aeroporto de Zurique, na Suíça, para aprovação da ampliação do aeroporto e a maior oposição estava, justamente, nas áreas mais ruidosas. $\mathrm{O}$ aeroporto de Helsink, na Finlândia, fica no município de Vantaa e o contorno de ruído ocupa $25 \%$ da área total do município, o que significa uma impossibilidade de ocupação do solo que não seja com uso logístico e industrial.

Nos EUA, os problemas com o ruído aeronáutico em aeroportos civis iniciaram na década de 60 , quando as comunidades afetadas pressionaram as autoridades aeroportuárias a estabelecer restrições com relação ao ruído. Em 1976, foi criada uma lei que determinou responsabilidades pelo impacto do ruído aeronáutico ao redor dos aeroportos, que foram alteradas ao longo dos anos. Essas leis federais formam a base para 0 controle do ruído aeronáutico e o programa de compatibilidade de uso do solo na Federal Aviation Regulation, FAR Part 150 (USA, 2004).

Na cidade de Chicago existem dois aeroportos que possuem programas voltados ao tratamento acústico das edificações impactadas pelo ruído aeronáutico: o O’Hare Airport e o Midway Airport. Na década de 80 foi iniciado um programa de tratamento acústico, com medições em algumas escolas e logo após, foram identificadas 27 escolas impactadas por valores a partir de $70 \mathrm{~L}_{\mathrm{DN}}$. As escolas que fazem parte do programa, atualmente 86, são monitoradas com medições internas e externas durante o período regular de atividades escolares. O programa é o mais abrangente e está entre os mais antigos dos EUA, sendo sustentado financeiramente por uma parte da tarifa de cada passagem aérea, 4,50 dólares, e por recursos da FAA.

\subsection{O RUÍDO NOS AEROPORTOS BRASILEIROS}

No Brasil, os estudos com a finalidade de identificar e propor soluções aos conflitos gerados pela implantação e operação dos aeroportos iniciaram na década de setenta, sendo, atualmente, de responsabilidade do DAC - Departamento de Aviação Civil - do Ministério da Aeronáutica. As restrições com relação à poluição sonora gerada pela operação das aeronaves, são estabelecidas pelo Plano de Zoneamento de Ruído, que é um documento normativo do Comando da Aeronáutica, estabelecendo restrições de uso do solo. Em 1987, foram instituídos os Planos de Zona de Proteção dos Aeródromos $P Z P A$, que podem ser básicos - PZPAB ou específicos - PZPAE e visam estabelecer parâmetros de segurança das operações de vôo e da comunidade vizinha através de gabaritos de altura das construções (IAC, 1998. v. 5, p. 4).

As Zonas de Proteção são elaboradas pelos Planos de Zoneamento de Ruído, determinados pela Portaria 1141 (BRASIL, 1987), na qual é definido que as áreas de impacto do ruído aeronáutico, são identificadas por três níveis:

a) Área I: interior à curva de nível de ruído 1 , onde o nível de incômodo sonoro é potencialmente nocivo aos circundantes, podendo ocasionar problemas fisiológicos, devido às exposições prolongadas;

b) Área II - Área do Plano de Zoneamento de Ruído, compreendida entre as curvas de nível de ruído $\mathrm{l}$ e 2 , onde são registrados níveis de incômodo sonoro moderado;

c) Área III - Área do Plano de Zoneamento de Ruído, exterior à curva de ruído de nível 2, onde normalmente não são registrados níveis de incômodo sonoro significativos.

Atualmente é utilizado, para determinação dos Planos Específicos, o software INM 6.1, para a geração das curvas isofônicas, e, os valores são emitidos em $L_{D N}$. Os valores são 
convertidos para IPR, através de uma equivalência, que ocorre da seguinte forma: $75 \mathrm{~L}_{\mathrm{DN}}$, para $63 \mathrm{IPR}$ e $65 \mathrm{~L}_{\mathrm{DN}}$, para 53 IPR. Porém, diferente de outros países que utilizam no mapeamento um número de curvas maior, no Brasil são utilizadas apenas duas curvas de nível de ruído, sendo que, pelos critérios publicados em publicação do IAC (1981), a curva 1 corresponde ao IPR 60 e, a curva 2, ao IPR 53.

A Portaria 1141/GM5 (BRASIL, 1987), capítulo XII, estabelece o Plano Básico de Zoneamento de Ruído, definindo critérios para determinação de duas curvas de nível de ruído, definidas em função do número de movimentos anuais do aeroporto. As curvas de ruído são consideradas limites das zonas I, II e III, onde é determinado o tipo de atividade permitida. Nas zonas I e II, as restrições de uso do solo são grandes, não sendo permitidos usos residenciais, educacional, de saúde e cultural. Os projetos arquitetônicos, para edificações dentro das áreas de ruído, devem ser submetidos ao Comando da Aeronáutica. Além do projeto arquitetônico, propriamente dito, deve ser apresentado o projeto de isolamento acústico, informando o isolamento acústico em $\mathrm{dB}$ para $500 \mathrm{~Hz}$, com detalhes construtivos de vedação das esquadrias e demonstração de atendimento à NBR 8572 (BRASIL, 1987).

A NBR 8572 (ABNT, 1984), estabelece os valores de redução de níveis de ruído para fachadas e coberturas de edificações localizadas na zona II. Para os maiores aeroportos brasileiros, como os de Confins, Congonhas, Galeão, Guarulhos e Salgado Filho, os valores são de 35 a $40 \mathrm{~dB}_{(\mathrm{A})}$.

Segundo o Instituto de Aviação Civil, desde 2003, existe uma grande possibilidade de acréscimo do impacto sonoro na América Latina, devido à proibição de operação de aeronaves mais antigas, com mais de 20 anos, na Europa e Estados Unidos. Restrições legais impedirão o trânsito de aeronaves ruidosas no corredor do Atlântico Norte, considerado o mais movimentado do mundo. Essas aeronaves tendem a ser vendidas e transferidas para empresas de países subdesenvolvidos, a um custo baixo e passariam a operar em países com uma legislação menos rigorosa no controle do ruído aeronáutico (IAC, 1998, v. 11, p. 25-29).

\subsubsection{O Aeroporto Internacional Salgado Filho}

Em setembro de 1923 foi concluída a construção do primeiro Aeroporto de Porto Alegre, e o local passou a ser conhecido por Aeródromo de São João, nome do bairro vizinho à área (INFRAERO, 2004).

A pista de pouso e decolagem possui $2.280 \mathrm{~m}$ de comprimento por $45 \mathrm{~m}$ de largura, com a mesma extensão desde a década de 50 , comportando operação de aeronaves com até 300 toneladas de peso. Tem um movimento médio diário de 140 aeronaves de vôos regulares, chegando e partindo de Porto Alegre. Atualmente, a restrição para vôos internacionais, ou de longo percurso, diretos, se explica pelo comprimento restrito da pista, que não oferece condições para a decolagem de aeronaves com o tanque de combustível cheio. A verba para a obra de ampliação da pista já está liberada, porém o que impede sua execução são as ocupações irregulares das vilas vizinhas.

O Aeroporto Salgado Filho possui um Plano Específico de Zoneamento de Ruído - PEZR - aprovado pela portaria 629/GM5, que institui os Planos Específicos de outros 89 Aeroportos brasileiros. O anexo LXXIV, da referida portaria, apresenta o Plano por meio de um desenho, utilizado até hoje pela Prefeitura Municipal de Porto Alegre, para definição do uso do solo nas zonas próximas ao Aeroporto.

Atualmente as aeronaves que operam no Salgado Filho, são em sua maioria, do tipo Boeing 737-300, 737500 e 737-700. Outros tipos de aeronave também operam no Aeroporto, como, por exemplo, o Air-Bus 320 e o Folker 100.

\section{MATERIAIS E MÉTODOS}

Para avaliar o incômodo e a percepção do ruído aeronáutico nas escolas, foram utilizados procedimentos 
de avaliação de desempenho acústico, com métodos quantitativos e qualitativos.

Os métodos quantitativos foram definidos a partir de levantamentos de campo, com medições acústicas e aplicação de questionários a alunos e professores, tendo a finalidade de coletar dados sobre a percepção do ruído por, parte da população, e quantificar os níveis de pressão sonora existentes nos locais.

Os métodos qualitativos incluem a realização de entrevistas com as diretoras e professores, e observações de comportamento e ocupação dos ambientes nas Escolas.

\subsection{OBJETOS DE ESTUDO}

$\mathrm{O}$ primeiro local encontrado foi a Escola Carlos Barbosa, que apresentou boas condições para instalação dos equipamentos, devido à existência de um pátio voltado para uma esquina, e uma forte exposição ao ruído da passagem dos aviões. Em um estudo exploratório, o ruído de fundo foi medido em 54,2 $\mathrm{dB}_{(\mathrm{A})}$. Também foram registradas as passagens de três aeronaves, com níveis máximos de ruído de 93,1, 91,7 e 89,2 $\mathrm{dB}_{(\mathrm{A})}$.

Depois de selecionar a Escola Carlos Barbosa, foi feito um levantamento de todos os estabelecimentos de ensino localizados nos bairros vizinhos ao Aeroporto, a partir de uma relação fornecida pela Secretaria de Educação do Estado do RS. No total, são 87 estabelecimentos de ensino localizados nos bairros vizinhos, sendo 41 particulares, com a função de creche ou escola infantil, 17 particulares, voltados para o ensino de $1^{\circ}$ e $2^{\circ}$ graus, 21 estabelecimentos estaduais e 8 municipais. Foram identificados 10 estabelecimentos de ensino dentro das zonas de ruído, sendo 2, dentro da Zona I: a Escola Carlos Barbosa e a Escola Lions Porto Alegre Farrapos. As duas Escolas, que se situam dentro da Zona I do PEZR, são Estaduais e voltadas para o Ensino Fundamental, do Pré até a $8^{\mathrm{a}}$ série, sendo que a Carlos Barbosa também possui atividade noturna com Educação de Jovens e Adultos.

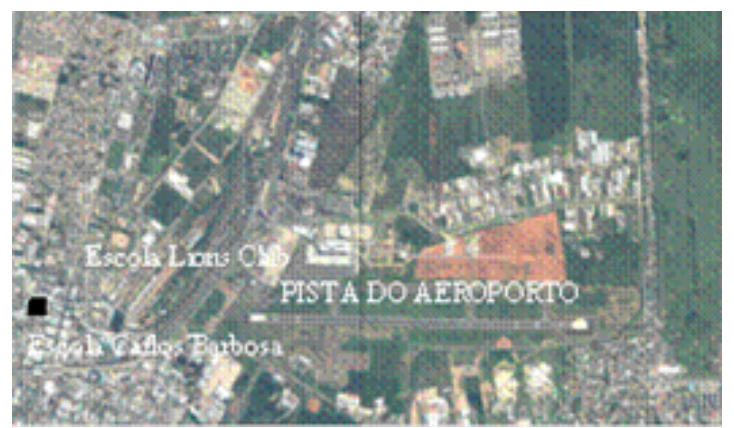

Figura 1: Localização das Escolas em relação à pista do Aeroporto. (Fonte: adaptado de PORTO ALEGRE, 2001)

A Escola Estadual Carlos Barbosa Gonçalves se localiza a, aproximadamente, $1600 \mathrm{~m}$ da cabeceira oeste da pista, no bairro Navegantes, e as aeronaves costumam passar acima do pátio, com o movimento predominante de aterrissagem.

A proximidade das aeronaves é muito grande e percebe-se o ruído emitido de forma muito intensa no pátio. A proximidade das aeronaves foi relatada por alguns moradores que já tiveram, inclusive, casos em que houve destelhamento de residências, em decorrência da passagem de aviões.

A escola foi fundada em 1957 e as atividades se desenvolviam em pequenos galpões de madeira, conhecidos como Brizoletas. O projeto do prédio atual é de 1984, desenvolvido dentro do projeto Escola Padrão de Alvenaria - EPA - da Secretaria de Obras do Estado. A construção é de alvenaria de tijolos aparentes, com cobertura de telha de fibrocimento e forro de madeira. $\mathrm{O}$ forro é a parte mais frágil da acústica do prédio, pois nas áreas de circulação é constituído de ripas intercaladas e, nas salas de aulas, o forro é convencional, no sistema macho/fêmea. Além de ser permeável ao ar, e conseqüentemente ao ruído, a espessura do forro não apresenta uma proteção acústica eficiente. Segundo informações da Secretaria de Obras, a finalidade dos espaços entre as ripas é facilitar a visualização de eventuais danos na cobertura.

A Escola Estadual Lions Club Porto Alegre Farrapos localiza-se a aproximadamente $1100 \mathrm{~m}$ da cabeceira oeste da pista, e assim como na Escola Carlos Barbosa, as aeronaves apresentam 
a mesma trajetória predominante, acima do pátio.

A escola foi fundada em 1968 e as atividades se desenvolviam em pequenos galpões de madeira de compensado. Alguns anos mais tarde, os galpões foram substituídos por outros de melhor qualidade, conhecidos como Brizoletas. O projeto do prédio atual é de 1989, desenvolvido dentro das diretrizes do Projeto Nova Escola - PNE - da Secretaria de Obras do Estado. A construção é de alvenaria de tijolos aparentes, com cobertura de telha de fibrocimento e forro de laje de concreto.

\subsection{MEDIÇÕES ACÚSTICAS}

O equipamento utilizado foi um medidor de nível de pressão sonora, tipo 1, marca QUEST, modelo 1900, com microfone original da marca $\mathrm{B} \& \mathrm{~K}$, onidirecional de $1 / 2$ polegada. $O$ equipamento foi fixado sobre tripé, a 1,20 $\mathrm{m}$ do solo.

Todos os eventos de ruído foram registrados, como os causados por veículos, buzinas, alarmes, sirenes, passagens de avião, com as informações de horário e tipo de aeronave, com análise posterior no gráfico global de ruído. Esse procedimento tem a finalidade de verificar a relação entre todos os tipos de eventos de ruído.

Como forma de validar os dados, foram realizadas, simultaneamente, medições de temperatura, umidade relativa e velocidade do ar, com equipamento QUEST TEMP 36.

Nas medições externas, buscou-se posicionar o equipamento em locais com menos obstruções físicas, porém com ocupação significativa de pessoas, para caracterizar a exposição ao ruído aeronáutico. Buscou-se também, atender ao requisito de absorção sonora do piso equivalente ao do concreto, conforme sugere a ISO 3891. Logo, os locais mais adequados para as medições externas foram as quadras esportivas.

As funções selecionadas para gerar as informações sonoras foram as seguintes: $\mathrm{L}_{\text {Aeq }}$ com integração de 1 segundo, $\mathrm{L}_{\max }$, $\mathrm{SEL}$, e os níveis estatísticos $\mathrm{L}_{10}$ e $\mathrm{L}_{90}$.

\subsection{QUESTIONÁRIOS}

O questionário para essa pesquisa foi formulado com o intuito de identificar o grau de incômodo, de alunos e professores, em relação ao ruído aeronáutico, e as perguntas foram redigidas tendo como base o resultado de entrevistas, com as diretoras e algumas professoras. Para tanto, seguindo recomendações de Lay e Reis (1994), o questionário foi confeccionado dentro dos seguintes condicionantes:

a) formato: curto para os alunos, contendo 4 perguntas fechadas e 2 perguntas abertas. Para os professores o formato adotado foi um pouco maior, contendo 7 perguntas fechadas e 4 perguntas abertas.

b) escalas de valores: para as perguntas fechadas foi utilizada uma escala bi-polar, com sim e não, e 1 questão de três pontos, onde houve a inclusão de um ponto neutro, possibilitando ao respondente manifestar sua indiferença ou descaso pelo assunto;

c) aplicação dos questionários: foi feita com a presença do pesquisador para garantir 0 preenchimento correto e o retorno imediato do material;

\subsection{ENTREVISTAS}

Foram realizadas entrevistas estruturadas, com um roteiro préestabelecido, para se obter uma idéia geral do objeto de estudo. As entrevistas foram feitas com as diretoras, vicediretoras e algumas professoras e também serviram como base para a estruturação dos questionários.

\subsection{OBSERVAÇõES}

O objetivo da utilização dessa técnica é o de identificar como os ambientes nas escolas são ocupados, fazendo um cruzamento com as respostas dos questionários. O tipo de observação utilizado nessa pesquisa é classificado, segundo Marconi e Lakatos (1999), como um trabalho de campo de observação sistemática e não participante. A observação sistemática, também 
conhecida como estruturada, pode ser organizada, segundo Lay e Reis (1994), a partir das seguintes definições:

a) seleção dos indivíduos: foram observados os alunos e professores;

b) definição de atividades: se as atividades são passivas ou ativas;

c) contexto: descrição de situações;

d) lugar: relação com o potencial de uso do lugar e real utilização por determinado grupo nas salas de aula e espaços de recreação.

\section{RESULTADOS OBTIDOS}

\subsection{MEDIÇÕES ACÚSTICAS}

$\mathrm{Na}$ Escola Carlos Barbosa, as medições foram realizadas em três períodos, caracterizando os três turnos de atividades da escola.

No período 1, turno da manhã, quando foram registrados 8 eventos, o ruído de fundo, caracterizado pelo $\mathrm{L}_{90}$, se manteve baixo, com o valor de $51,6 \mathrm{~dB}_{\mathrm{A}}$. A figura 1 mostra o registro dessa medição, onde o retângulo destaca 0 perfil gráfico dos eventos de ruído aeronáutico. O nível máximo atingido foi de $99,1 \mathrm{~dB}_{\mathrm{A}}$. O gráfico global do período 2 está na figura 2 , onde foram registrados 24 eventos, sendo 12 de aeronaves de grande porte. A figura 3 mostra o registro do ruído no período entre 17 e 22 horas, onde foram registrados 36 eventos, sendo 19 de aeronaves de grande porte.

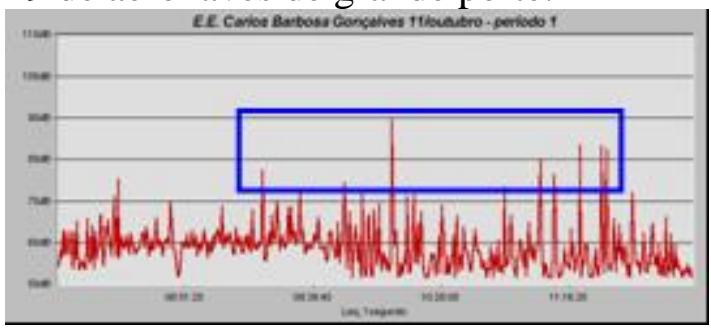

Figura 2: Resultado global da medição de ruído no período 1 , do dia 11 de outubro.

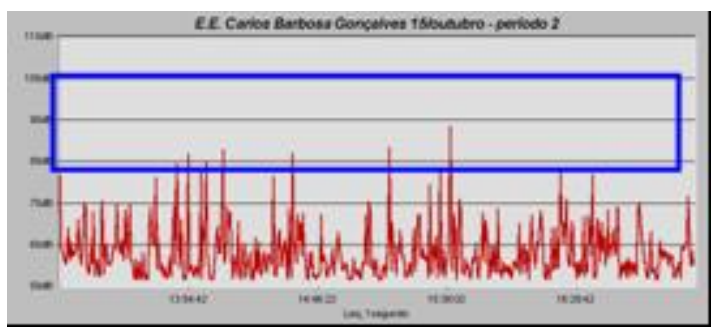

Figura 3: Resultado global da medição de ruído no período 2, do dia 15 de outubro.

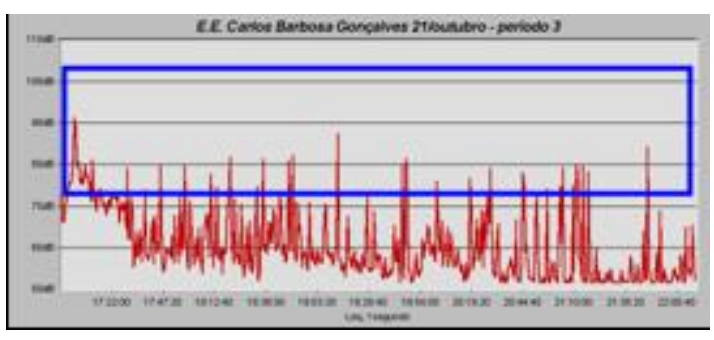

Figura 4: Resultado global da medição de ruído no período 3, do dia 21 de outubro.

Analisando-se os três gráficos, percebe-se o destaque do ruído produzido pela passagem das aeronaves, pois são, na grande maioria das vezes, superiores a $75 \mathrm{~dB}_{\mathrm{A}}$, e diferem completamente do ruído de fundo típico da área.

Os dados das três medições estão expostos na tabela 3 , onde o ruído de fundo, caracterizado pelo $\mathrm{L}_{90}$, apresentase com o valor de $51,6 \mathrm{~dB}_{\mathrm{A}}$.

De um modo geral, os níveis de ruído podem ser classificados como inadequados, pois, além de excederem em bem mais de $5 \mathrm{~dB}_{\mathrm{A}}$ ao ruído de fundo, desqualifica acusticamente a área para a atividade escolar.

Tabela 3: Resumo das medições na Escola Carlos Barbosa

\begin{tabular}{|c|c|c|c|c|c|c|}
\hline Data & $\mathbf{T}$ & $\mathbf{L}_{\text {Aeq }}$ & $\mathbf{L}_{\mathbf{m a x}}$ & $\mathbf{L}_{\mathbf{9 0}}$ & $\mathbf{S E L}$ & $\mathbf{N E}$ \\
\hline $\begin{array}{c}11 \\
\text { NOV }\end{array}$ & 1 & 66,7 & 99,1 & 51,6 & 108,3 & 8 \\
\hline $\begin{array}{c}15 \\
\text { NOV }\end{array}$ & 2 & 67,1 & 96,8 & 51,6 & 108,9 & 24 \\
\hline $\begin{array}{c}22 \\
\text { NOV }\end{array}$ & 3 & 71,4 & 100,4 & 51,6 & 114,1 & 36 \\
\hline
\end{tabular}

T - turno da medição; NE - número de eventos de ruído aeronáutico registrado durante a medição.

Na Escola Lions Club foi realizada uma medição de 2 horas, onde foram registrados 13 eventos de passagem de aeronaves, sendo que, 7 foram de aeronaves de grande porte.

O ruído de fundo também foi baixo, com valor de 51,6 $\mathrm{dB}_{\mathrm{A}}$, e o ruído da passagem das aeronaves se destaca em relação às outras fontes da área, como mostra a figura 4, onde o retângulo marca os picos de ruído aeronáutico.

A tabela 4 mostra os valores das medições na Escola Lions Club, destacando-se o nível máximo, $\mathrm{L}_{\max }$, de $110,4 \mathrm{~dB}_{(\mathrm{A})}$. 


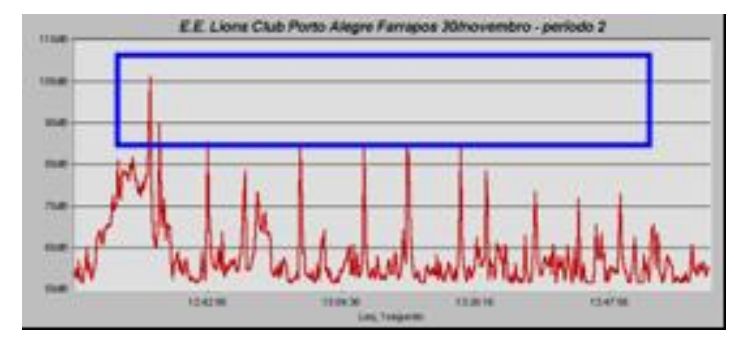

Figura 5: Resultado da medição de ruído na Escola Lions Club.

Tabela 4: Resumo das medições na Escola Lions Club

\begin{tabular}{|c|c|c|c|c|c|c|}
\hline Data & $\mathbf{T}$ & $\mathbf{L}_{\text {Aeq }}$ & $\mathbf{L}_{\max }$ & $\mathbf{L}_{\mathbf{9 0}}$ & SEL & NE \\
\hline $\begin{array}{c}30 \\
\text { NOV }\end{array}$ & 2 & 75,6 & 110,4 & 51,6 & 113,5 & 13 \\
\hline
\end{tabular}

$\mathrm{T}$ - turno da medição; NE - número de eventos de ruído aeronáutico registrado durante a medição.

\subsection{QUESTIONÁRIOS}

Na Escola Carlos Barbosa, 105 alunos de $3^{\mathrm{a}}, 4^{\mathrm{a}}$ e $6^{\mathrm{a}}$ séries do ensino fundamental responderam ao questionário.

A primeira pergunta procurou avaliar o grau de incômodo do ruído dos aviões nas atividades em sala de aula. Para 64\% dos alunos, a interferência é grande, enquanto que 30\% manifestaram indiferença com relação ao problema.

As duas questões seguintes procuraram avaliar os dois tipos de comportamento mais comum em relação ao ruído excessivo: alteração do volume da voz por parte da professora e interrupção da comunicação entre 0 professor e o aluno. Nessa questão, 81\% dos alunos revelaram que já precisaram elevar o volume de voz para continuar a comunicação durante a passagem dos aviões, enquanto que $77 \%$ já deixaram de ouvir a professora.

A última pergunta dirigida aos alunos, teve a finalidade de confrontar o incômodo acústico de suas casas e da escola, uma vez que os alunos residem muito próximo à Escola, em locais com relevante exposição ao ruído. Para essa questão, $78 \%$ dos alunos referem a Escola como o ambiente mais ruidoso. Alguns alunos manifestaram, durante a aplicação dos questionários, que na Escola, o ruído dos aviões incomoda menos, porque existem outras fontes de ruído em sala de aula, que diminuem a percepção do ruído dos aviões.
A maioria dos alunos da Carlos Barbosa considera que a biblioteca e a sala de vídeo são os locais mais silenciosos da escola. O gráfico a seguir mostra a porcentagem de respostas dadas para cada ambiente da escola. Vale lembrar que essa era uma pergunta aberta, onde os alunos poderiam colocar o nome de qualquer lugar da escola. Dentro dessa possibilidade, $19 \%$ dos alunos respondeu que nenhum local na escola é silencioso.

Quando questionados sobre qual seria o local mais ruidoso da escola, também uma pergunta aberta, não houve uma variedade tão grande de resposta, como na pergunta anterior, e 60\% indicaram a sala de aula como o lugar com maior ruído.

Ainda na Escola Carlos Barbosa, 10 professores responderam ao questionário. Todos manifestaram que o incômodo é muito grande com relação ao ruído dos aviões, que precisam falar mais alto e deixam de escutar os alunos devido à passagem dos aviões. Para a maioria dos professores, não existe ambiente silencioso na escola e o local onde o ruído incomoda mais é na sala de aula. Todos os professores também responderam que, na sua opinião, o ruído prejudica o rendimento escolar dos alunos.

Na Escola Lions Club 117 alunos de $2^{\mathrm{a}}, 3^{\mathrm{a}}, 4^{\mathrm{a}}$ e $6^{\mathrm{a}}$ séries, responderam ao questionário. Com relação à interferência do ruído nas atividades em sala de aula, $68 \%$ dos alunos opinaram que o barulho dos aviões incomoda muito, enquanto que $26 \%$ manifestaram indiferença ao ruído.

Para as questões que avaliam a interferência na comunicação entre aluno e professor, $79 \%$ afirmam que já precisaram falar mais alto em função da passagem dos aviões e $72 \%$ já deixaram de ouvir a professora durante a aula. Alguns alunos responderam que não deixaram de ouvir a professora, mas reportaram que a professora pára de falar quando o avião passa.

Em comparação ao ruído da sua casa, $78 \%$ afirmaram que a escola é mais ruidosa. 
Para a maioria dos alunos, os locais mais silenciosos da escola são a biblioteca e o banheiro, e para $18 \%$ dos, alunos nenhum lugar é silencioso.

Assim como na Carlos Barbosa, os alunos apresentaram menor variedade de respostas quando foram questionados sobre qual seria o lugar com mais barulho, e a sala de aula foi o local indicado pela maioria.

Também na Escola Lions Club, o grupo de professores manifestou de forma mais direta o grande transtorno do ruído aeronáutico nas atividades em sala de aula. Os 14 professores que responderam ao questionário, classificaram o incômodo como alto e afirmaram que as interrupções na comunicação com os alunos ocorrem com freqüência, pois é necessário interromper a fala, enquanto o avião passa, para não prejudicar a voz. Todos os professores avaliaram que o ruído dos aviões influencia no desempenho escolar.

\subsection{ENTREVISTAS}

Para a diretora da Escola Carlos Barbosa, a passagem dos aviões gera alterações nas atividades escolares e na ocupação dos espaços. Nas sextas-feiras à tarde são programadas apenas atividades recreativas, não são dadas aulas expositivas, nem aplicadas provas, pois é nesse período que ocorre o maior fluxo de aeronaves. Para a diretora, o $2^{\circ}$ andar é o local onde o ruído gera maior incômodo. Anteriormente, as turmas dos alunos maiores, $7^{\mathrm{a}}$ e $8^{\mathrm{a}}$ séries, tinham aulas no $2^{\circ}$ pavimento, porém foi detectada uma agitação maior por parte dos alunos. Então, os alunos mais novos passaram a ocupar o $2^{\circ}$ pavimento, por serem mais disciplinados. Os professores, em comparação aos alunos, são os que demonstram menor tolerância ao ruído, havendo manifestações claras de dificuldade de concentração nos dias de maior fluxo de aeronaves. Na opinião da diretora, o ruído atrapalha o desempenho escolar, no momento que induz freqüentemente à interrupção na comunicação entre professor e aluno.

Os professores entrevistados ressaltaram que a interrupção no raciocínio, durante uma narrativa para as crianças menores, prejudica o raciocínio lógico dos alunos.

A professora responsável pela biblioteca relatou que, atualmente, a situação acústica é muito boa, pois na época em que o prédio era de madeira, além do ruído, havia tremores com casos de queda de janelas em cima dos alunos.

Com relação à diferença de desempenho escolar entre os alunos da Carlos Barbosa e alunos de outras escolas, as opiniões foram divergentes. A professora da $3^{\mathrm{a}}$ série disse que a diferença de desempenho se deve à fatores sócio-econômicos, pois ela leciona na Escola Estadual Danilo Antonio Zaffari, também no bairro Navegantes, e ela afirma que na Carlos Barbosa os alunos tem uma condição bem melhor, apesar de estarem mais expostos ao ruído. As outras respostas foram no sentido de afirmarem que o desempenho é pior na Carlos Barbosa e alguns professores disseram que não existe diferença de desempenho.

Além do ruído excessivo, a proximidade das aeronaves é outro fator que causa surpresa para quem permanece no pátio da escola. Já houve tentativa, por parte dos professores, de alertar a Secretaria de Educação do Estado sobre o excesso de ruído, porém nenhuma medida foi tomada. Os professores relataram que houve uma breve medição no local há alguns anos, em que se chegou à conclusão de que a situação não era relevante.

A diretora da Escola Lions Club afirmou que não existem alterações no uso dos espaços em função do tráfego das aeronaves. $\mathrm{O}$ local que gera maior incômodo em relação ao ruído é o pavilhão de madeira, que chega a vibrar com a passagem de determinadas aeronaves. Os professores são os que demonstram maior intolerância com o ruído, pois, na opinião da diretora, as crianças convivem há mais tempo com o problema em função de morarem muito próximo ao aeroporto.

A escola já alertou à Secretaria de Obras do Estados sobre o excesso de ruído, mas nada foi feito. 
O professor de educação física, que dá aula todas as manhãs, é o mais exposto ao ruído das aeronaves. Ele relata que as atividades são muito prejudicadas e já sabe distinguir as empresas que possuem as aeronaves mais barulhentas, os horários e dias de maior ruído.

Os professores também foram questionados com relação à diferença de desempenho escolar entre os alunos da Lions Club e alunos de outras escolas. A professora da $2^{\mathrm{a}}$ série do turno da tarde afirmou que a diferença é muito grande, tendo relatado que há muita dificuldade com os alunos da Lions Club, em comparação com os alunos de outras duas escolas em que leciona, e acredita que o trânsito das aeronaves é o grande causador do fraco desempenho das turmas. Já a psicóloga, que também trabalha com alunos de outras escolas, relatou que não nota diferença entre 0 rendimento dos alunos nas escolas mais e menos expostas ao ruído, mostrando alguma indiferença com o assunto.

\subsection{OBSERVAÇÕES}

$\mathrm{Na}$ Escola Carlos Barbosa observou-se, no interior da sala de aula, a interrupção da comunicação alunoprofessor, no momento de passagem da aeronave e a conseqüente adaptação ao evento. No pátio, o ruído chama a atenção, assim como a proximidade das aeronaves, que podem ser visualizadas, desviando a atenção das atividades recreativas.

De um modo geral, foi observado que os alunos, na Escola Carlos Barbosa, tem um comportamento relativamente disciplinado em sala de aula. Durante a aplicação dos questionários, os alunos se concentraram em responder às perguntas, ficando em silêncio durante esse tempo. Andando pelos corredores no período de aula, não se observa interferência do som das atividades das salas de aula.

A observação na Escola Lions Club foi feita no pátio da Escola e nas salas de aula durante a aplicação dos questionários.

Em sala de aula, com exceção da $2^{\mathrm{a}}$ série, observou-se que o ambiente é muito ruidoso. Durante a passagem dos aviões, os alunos elevam o volume de voz e continuam falando o tempo todo, sendo que apenas a professora interrompe a comunicação.

Na ocupação do pátio existe uma distinção em relação à faixa etária e turno dos alunos. Os alunos da manhã ocupam o pátio, predominantemente, nos períodos de educação física, enquanto que os do turno da tarde utilizam o pátio também na hora do recreio. Foi notada uma reação intensa ao ruído da passagem de dois aviões caça da Aeronáutica, quando algumas crianças interromperam a recreação, sendo que duas crianças tamparam os ouvidos com as mãos e uma delas correu assustada, em direção ao prédio da escola.

De um modo geral, o ambiente na Escola Lions Club apresenta maior agitação e indisciplina por parte dos alunos, sendo mais ruidoso, em relação à Escola Carlos Barbosa.

\section{CONSIDERAÇÕES SOBRE OS RESULTADOS}

O comportamento observado dos alunos das duas escolas foi diferente, pois os alunos da Lions são bem mais agitados do que os alunos da Carlos Barbosa, embora em ambas as escolas, os resultados dos questionários dos alunos e professores tenham sido similares.

Foi notado um ambiente mais ruidoso na Lions, em comparação com a Carlos Barbosa. Uma possibilidade é com relação ao tipo de superfície do forro: na Carlos Barbosa o forro é de madeira e na Lions é de concreto, uma superfície com menor coeficiente de absorção sonora, o que torna $\mathrm{o}$ ambiente com maior reverberação.

Existe um indicativo muito forte de que o ruído nessas escolas possa causar problemas vocais e auditivos, pois, como foi indicado nas respostas dos questionários, a maioria dos respondentes já teve que elevar o volume de voz para poder se comunicar. Levando-se em consideração que, para a voz ser audível, é preciso elevar em $10 \mathrm{~dB}_{\mathrm{A}}$ acima do ruído do ambiente, os alunos e professores no pátio, teriam que falar com um nível de pressão sonora próximo 
a $80 \mathrm{~dB}_{\mathrm{A}}$, acarretando um esforço vocal acima do desejável.

Outro aspecto levantado pelos questionários e entrevistas diz respeito à interrupção na comunicação entre professor e aluno, causando prejuízo no desempenho escolar. Pode-se afirmar que cada interrupção dura em torno de 10 segundos, tempo mínimo considerado para um evento de ruído aeronáutico. Conforme se verificou durante uma das medições na Escola Carlos Barbosa, foram registrados 19 eventos de aeronaves de grande porte, resultando numa interrupção da comunicação professor-aluno, de aproximadamente 3 minutos de duração, promovendo a interrupção do raciocínio. Ressaltando-se que o evento ocorre de forma imprevista e em intervalos de tempo descontinuados de 10 segundos, não é possível uma ação preventiva, que dê continuidade na comunicação entre aluno-professor

Em ambas as escolas, a indicação do ambiente mais silencioso no questionário teve uma grande variedade de respostas, salientando uma porcentagem significativa de alunos que afirmam que não existe lugar silencioso na escola, $18 \%$ na Lions e $19 \%$ na Carlos Barbosa. Uma curiosidade é que, nas duas escolas, os locais apontados como os mais silenciosos, a biblioteca, no Lions e a sala de vídeo, na Carlos Barbosa, localizam-se nos setores com menor qualidade acústica construtiva. Esses ambientes, porém, possuem um uso diferenciado: a biblioteca é utilizada em apenas um período por semana por turma e os alunos, obrigatoriamente, devem fazer silêncio. A sala de vídeo da Carlos Barbosa é o local mais exposto ao ruído, pois fica no $2^{\circ}$ pavimento, e é indicado como um dos mais silenciosos. No projeto original da escola, a sala era destinada para aulas, porém a direção da escola resolveu transformá-la em uma sala de uso eventual, justamente devido à maior exposição ao ruído. Os questionários mostraram uma forte relação entre tempo de exposição ao ruído e incômodo gerado pelos aviões, pois as salas apontadas como mais silenciosas, na verdade, tem um tempo de uso bem menor do que a sala de aula.

\section{REFERÊNCIAS BIBLIOGRÁFICAS}

ABNT - ASSOCIAÇÃO BRASILEIRA DE
NORMAS TÉCNICAS. Fixação de valores
de redução de nível de ruído para
tratamento acústico de edificações
expostas ao ruído aeronáutico. NBR 8572.
Rio de Janeiro, 1984. 8 p.

ABNT - ASSOCIAÇÃO BRASILEIRA DE NORMAS TÉCNICAS. Ruído Aeronáutico - Terminologia. TB 389. Rio de Janeiro, 1990. $10 \mathrm{p}$.

ALVES, Cláudio J. P. Avaliação de impactos. São José dos Campos: ITA, Notas de Aula. 2003.

BERTOLI, S. R.; KOWALTOWSKI, D. C. C.; BARROS, L. A. F. Avaliação de desempenho acústico em creches de conjunto habitacional de interesse social: o caso de projetos padrão. In: V ENCAC, 1999, Fortaleza. Anais do V ENCAC 99. Fortaleza: Antac, 1999.

BOMAN, E.; ENMARKER, I. Factors affecting pupils' noise annoyance in schools: the building and testing of models. Environment and Behavior. 36 (2), 207228. 2004.

BRASIL. Ministério da Aeronáutica. PORTARIA $\mathrm{N}^{\circ} 1.141 / \mathrm{GM} 5$ de 8 de dezembro de 1987. Dispõe sobre Zonas de Proteção e Aprova o Plano Básico de Zona de Proteção de Aeródromos, o Plano Básico de Zoneamento de Ruído, o Plano Básico de Zona de Proteção de Helipontos e o Plano de Zona de Proteção de Auxílios à Navegação Aérea e dá outras providências.

COHEN, S.; EVANS, G. W.; KRANTZ, D. S.; STOKOLS, D. Physiological, motivational, and cognitive effects of aircraft noise on children: moving from the laboratory to the field. American Psycologist. 35 (3), p. 231-243, 1980.

FARINA, A. Metrologia del rumore da aeromobili, certificazione acustica e impatto sul território. Bolletino degli Ingegneri della Toscana, Firenze, n. 10, ano XLII, 25 p., out. 1995.

FISCHER, Vera L.B. Ambiente escolar, usuários e contexto urbano. Porto Alegre, 2000. 209p. Dissertação (Mestrado em Planejamento Urbano e Regional) - Programa 
de Pós-Graduação em Planejamento Urbano e Regional, Universidade Federal do Rio Grande do Sul.

GARCIA, A. ; FAUS, L. J. ; GARCIA, A. $M$. The community response to aircraft noise around six spanish airports. Journal of Sound and Vibration, 164 (1), p. 45-42, 1993.

GERGES, S. N. Y. Ruído : fundamentos e controle. Florianópolis: S. N. Y. Gerges, 2000. $696 \mathrm{p}$.

GIFFORD, Robert. Educacional Environmental Psychology. In: GIFFORD, R. Environmental Psychology: principles and practice. USA: Published by Allyne Bacon, 1998.

GÜLLER, M.; GÜLLER, M. Del aeropuerto a la ciudad aeropuerto. Barcelona: Gustavo Gili, 2002. 190 p.

IAC - Instituto de Aviação Civil. Divisão de Instrução Profissional. Planejamento urbano no entorno de aeroportos. Rio de Janeiro: Ministério da Aeronáutica - IAC, 1998 (Apostila do Curso). 17v.

IAC - Instituto de Aviação Civil. Divisão de Relacionamento Urbano. Métodos de avaliação dos níveis de ruído e de incômodo gerados pela operação de aeronaves em aeroportos. Rio de Janeiro: Ministério da Aeronáutica - IAC, 1981. 107 p. (Boletim Técnico - IAC 4102-0581).

ICAO - International Civil Aviation Organization. Committee on Aviation Environmental Protection. Environmental technical manual on the use of procedures in the noise certification of aircraft. Montreal: ICAO, 2000. 117 p.

INFRAERO - Empresa Brasileira de InfraEstrutura Aeroportuária. A política ambiental da INFRAERO. Brasília: Ministério da Aeronáutica, 2002. Disponível em: <http://www.infraero.gov.br> Acesso em: 08 de fevereiro de 2004.

ISO - International Organization for Standardization. Acoustics: procedure for describing aircraft noise heard on the ground, ISO 3891. Switzerland, 1978. 24 p.

JIGGINS, Mark; BERRY, Bernard F. Aircraft noise at school and children's cognitive performance and stress responses: the west london schools study. National Physical Laboratory, 2001. 46p. (Aircraft Noise Measurements and Personal Dosimetry, NPL Report CMAM 68).
LAY, M.C.D; REIS, A.T. Métodos e técnicas para levantamentos de campo e análise de dados: questões gerais. In: WORKSHOP AVALIAÇÃO PÓSOCUPAÇÃO, 1994, São Paulo. Anais... São Paulo: ANTAC/NUTAU, 1994. 96 p. p. 2849.

LOSSO, M. A. F. Qualidade acústica de edificações escolares em Santa Catarina: avaliação e elaboração de diretrizes para projeto de implantação. Florianópolis: UFSC, 2003. 168f. Dissertação (Mestrado em Engenharia de Produção) - Programa de PósGraduação em Engenharia de Produção, Universidade Federal de Santa Catarina.

MATSUI, T.; Uehara, T.; Miyakita, T.; Hiramatsu, K.; Osada, Y.; Yamamoto, T. The Okinawa study: effects of chronic aircraft noise on blood pressure and some other physiological indices. Journal of Sound and Vibration. 277, 469-470, 2004.

MAXWELL, L. E.; EVANS, G. W. The effects of noise on pre-school children's prereading skills. Journal of Environmental Psychology. 20, 91-97, 2000.

MUZET, A. Aircraft noise and sleep. Bonn: PAIXÃO, D.X. Análise das condições acústicas em sala de aula. Santa Maria:

UFSM, 1997. 208f. Dissertação (Mestrado em Educação) - Programa de Pós-Graduação em Educação, Universidade Federal de Santa Maria, 1997.

PORTO ALEGRE. Imagens de satélite da cidade de Porto Alegre. Porto Alegre: PMPA, 2001.

SANCHO, V.; SENCHERMES, A. G. Curso de acústica em arquitectura. Madrid: Colégio Oficial de Aquitectos de Madrid, 1982. 215 p.

SANTOS, Maria J. O. Ruído no ambiente escolar: causas e conseqüências. Rio de Janeiro, 1993. 205f. Dissertação (Mestrado em Arquitetura e Urbanismo) - Programa de Pós-Graduação em Arquitetura e Urbanismo da Universidade Federal do Rio de Janeiro.

SANTOS, U. P. Ruído: riscos e prevenção. São Paulo: Hucitec, 1999. 157 p.

USA. Federal Aviation Administration Department of Transports. Aeronautics and space, volume 1, capítulo 1, parte 150. Airport Noise Compatibility Planning. Eletronic Code of Fedral Regulations. Disponível em: <http://ecfr.gpoaccess.gov/ 
cgi/t/text/text-idx?c=ecfr\&sid=6ee38...>

Acesso em: 26 de fevereiro de 2004.

VALLET, Michel. Caractéristiques et indicateurs de la gêne due au bruit des avions. Synthèse INRET $n^{\circ} 29$ de junho de 1996. Disponível em: $<$ http//www.ufcna.com/mesurebruit1.html $>$ Acesso em: 08 de fevereiro de 2004.

VINCENT, B.; VALLET, M.; OLIVIER, D.; PAQUE, G. Evaluation of variations of the annoyance due to aircraft noise. In: The $29^{\text {th }}$ International Congress and Exhibition on Noise Control Engineering, 2000, Nice. Inter-noise 2000. Nice: SFA.

WALLIS, Allan D. Airport noise monitoring: a review. Aircraft Engineering and Aerospace Technology: An International Journal, Emerald Group Publishing Limited, Volume 69, nº 2, p. 112-118, 2002.

WHO - European Center for Environment and Health. Bonn Office. Technical meeting on aircraft noise and health. Bonn, 2001. Relatório. 